and if necessary performing a duodenotomy, so the common bile duct is not damaged. In our patient a short-circuit was performed and not excision because of the difficulty of operation. Cattell \& Mudge (1952) reported an $8 \%$ mortality rate for operations on duodenal diverticula, but in the recent series of Landor \& Fulkerson (1966) six cases were operated on without a fatality.

\section{Summary}

The association of jaundice with duodenal diverticula is discussed and a case with obstructive jaundice due to a peri-Vaterian diverticulum is reported. Cholangitis, secondary to bacterial contamination of the diverticulum, may have been a contributory factor.

\section{Acknowledgment}

We would like to thank Mr R. H. Franklin for permission to publish this case.

\section{References}

Cattell, R.B. \& Mudge, T.J. (1952) The surgical significance of duodenal diverticula. New Engl. J. Med. 246, 317.

HARTLEY, F.K. (1962) Biliary obstruction: A case of common bile duct obstruction as a complication of a duodenal diverticulum. J. Kans. med. Soc. 63, 51.

Hobbs, J.R., Campbell, D.M. \& Scheuer, P.J. (1966) The clinical value of serum 5 nucleotidase assay. Enzym. Biol. Clin. 6, 182.

Jones, T.W. \& Merendino, K.A. (1960) The perplexing duodenal diverticulum. Surgery, 48, 1068.

LANDOR, J.H. (1966) Diverticula of the small intestine. Missouri Med. 68, 42.

LANDOR, J.H. \& FulKerson, C.C. (1966) Duodenal diverticula. Relationship to biliary tract disease. Arch. Surg. 93, 182.

LANE, D. (1960) Primary duodenal diverticula and their problems. Aust. N.Z. J. Surg. 30, 63.

Neill, S.A. \& Thompson, N.W. (1965) The complications of duodenal diverticula and their management. Surg. Gynec. Obstet. 120, 1251.

Rosenthal: in Odgers, P.N.B. (1930) Duodenal diverticulosis. Brit. J. Surg. 17, 592.

Wнiтсомв, J.G. (1964) Duodenal diverticulum; A clinical evaluation. Arch. Surg. 88, 275.

Wilbur, B.C., Reimer, G.W. \& Cressman, R.D. (1956) Duodenal diverticula in common duct disease. Amer. $J$. Surg. 92, 318.

\title{
Solitary myeloma of the skull, causing bilateral exophthalmos
}

\author{
I. J. T. DAVIES* \\ M.B., M.R.C.P. \\ Medical Registrar, \\ Whittington Hospital, London, N.19
}

SOLITARY myeloma (plasmocytoma) of bone rarely occurs. In a review of the literature, Raven \& Willis (1949) found nineteen authenticated cases, sixteen of which were males. The commonest bone to be involved was the femur and the next commonest the humerus. Involvement of the skull was not recorded. The following case illustrates a solitary myeloma which involved both orbits, causing bilateral exophthalmos.

\section{Case report}

A woman aged 73 presented in 1963 with leftsided exophthalmos and a soft tissue mass in the region of the left temporalis muscle. She had rapidly developed visual loss in both eyes. Examination revealed pulsating exophthalmos with primary optic atrophy on the left and a pulsatile tumour in the region of the left temporalis muscle. The tumour was $3 \times 2 \mathrm{~cm}$ and was soft. The edges of the skull could be felt surrounding it.

\footnotetext{
* Present address: University College Hospital, Gower Street, London, W.C.1.
}

$\mathrm{X}$-ray of the skull showed a large defect in the frontal bone with destruction of part of the sphenoid. There was also destruction of the zygoma and left side of the orbit.

A clinical diagnosis of secondary carcinoma was made, although no primary site could be found. Routine blood count was normal, and the sedimentation rate was $70 \mathrm{~mm}$ in $1 \mathrm{hr}$. She received a course of X-ray therapy to the pulsatile swelling with considerable regression of the mass.

In May 1966 she was found to have severe bilateral exophthalmos and optic atrophy (Fig. 1). Pupillary light reflexes were absent. The swelling over the left temporalis muscle had not recurred. The sedimentation rate was $90 \mathrm{~mm}$ in $1 \mathrm{hr}$, there was no myeloma band in an electrophoretic strip of the plasma proteins and at no time was there any Bence Jones protein in the urine. X-ray of the skull showed that osteolytic bone destruction had extended to involve both orbits. Three months after admission she developed bronchopneumonia and died. 


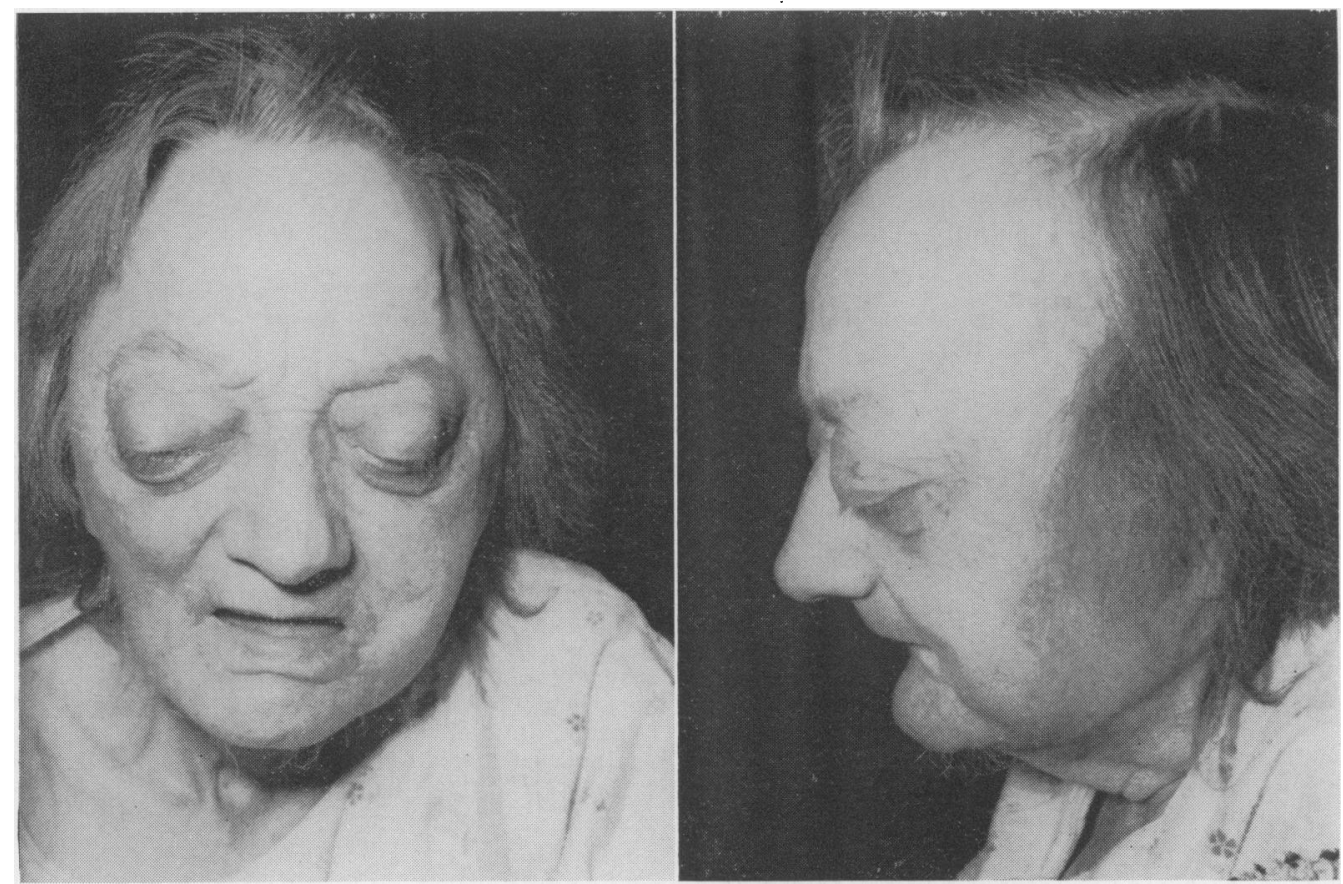

Fig. 1. Bilateral exophthalmos due to a solitary myeloma involving both orbits.

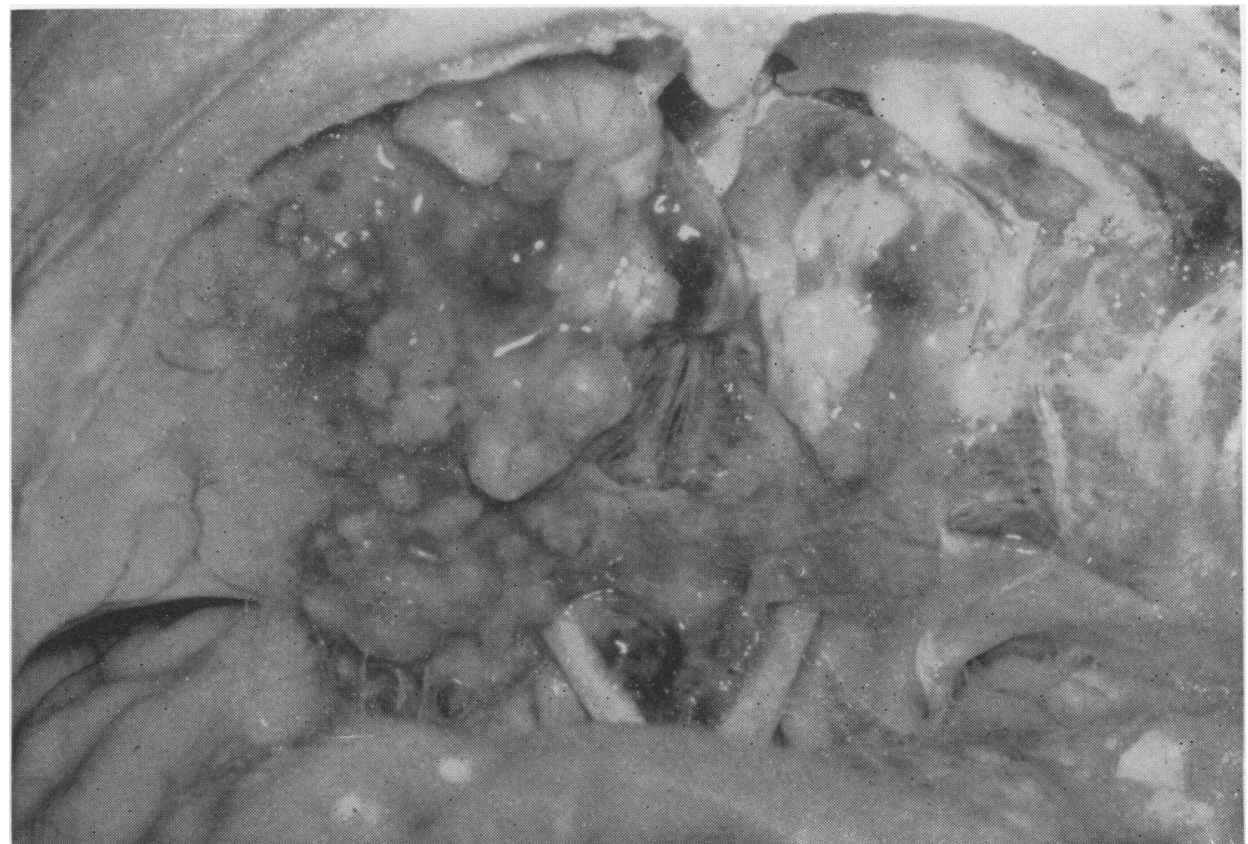

Fig. 2. Post mortem appearance after opening the skull. The solitary myeloma is seen infiltrating the roof of both orbits. 


\section{Necropsy}

There was erosion of both frontal bones and sphenoid with firm, haemorrhagic tumour which was well encapsulated. The tumour infiltrated both orbits and into the left maxillary antrum (Fig. 2). There was fibrosis of the pituitary and atrophy of the optic chiasma and nerves. No myeloma deposits were seen elsewhere in the skeleton. Histological examination showed the tumour to be a typical myeloma. Examination of the bone marrow did not reveal any increase in the number of plasma cells.

\section{Discussion}

Willis (1960) has stressed the difficulty of bsing certain that an apparently solitary myeloma is not, in fact, a precocious first lesion of myelomatosis. The disseminated nature of myelomatosis usually becomes manifest within 2 years of the first appearance of a single myeloma. However, there have been several reports of up to 12 years elapsing between initial presentation as a single myeloma and dissemination occurring (Yentis, 1956 ; Lumb, 1952).

Willis (1960) has suggested that a solitary myeloma may reasonably be presumed if there is:

(a) a long history, (b) histological confirmation, (c) extensive radiological surveys, and (d) postmortem evidence.

This case fulfills most of the criteria for inclusion in the group of solitary myeloma of bone. There was a 3-year history, histological evidence of the nature of the single tumour and no evidence of any other medullary lesion in the skeleton at autopsy.

Although involvement of the skull is so characteristic of myelomatosis it is of interest that the skull is so rarely involved by a solitary myeloma. A search of the literature has shown three recorded cases of orbital involvement (Jim, 1955 ; Cogan, 1956; Björnberg, 1962); but none in which both orbits have been invaded by a solitary myeloma.

\section{Summary}

A case of solitary myeloma of bone involving both orbits is presented and discussed.

\section{Acknowledgment}

I am grateful to Dr T. St M. Norris, for permission to publish this case.

\section{References}

BJORNBERG, K. (1962) Extramedullary plasmocytoma of the orbit. Acta ophthal. (Kbh.), 40, 330.

Cogan, J.F. (1956) Extramedullary plasmocytoma of the orbit. Brit. J. Ophthal. 40, 681.

Jim, V.K.S. (1955) Plasmocytoma of the orbit. Amer. J. Ophthal. 39, 43.

LumB, G. (1952) The pathology of the myelomata (plasma cell tumours). Ann. Roy. Coll. Surg. 10, 241.

RAVEN, R.W. \& Willis, R.A. (1949) Solitary plasmocytoma of the spine. J. Bone Jt Surg. 31-B, 269.

Willis, R.A. (1960) Pathology of Tumours. Butterworth, London.

YENTIS, I. (1956) The so-called solitary plasmocytoma of bone. J. Fac. Radiol. (Lond.), 8, 132.

\section{A case of aortic arch syndrome of Takayasu due to disseminated lupus erythematosus}

\author{
M. D. SWALlow \\ M.B., Ch.B. \\ Lately Medical Registrar, \\ Northern General Hospital, Sheffield
}

THE aortic arch syndrome of Takayasu, variously called 'pulseless disease', 'reversed coarctation', Martorell syndrome and branchial arteritis, is found in young people, mostly women. It is characterized by thrombosis of the vessels arising from the arch of the aorta and causes cerebral, ocular and ischaemic symptoms in the upper extremities. Its aetiology and pathogenesis are obscure (Strachan, 1966).

The case of aortic arch syndrome presented below is interesting because the patient sub-

Address for reprints: 58 Greenfield Crescent, Waverton, Chester.

\author{
J. BEASLEY \\ M.B., B.S., D.P.H. \\ Lately Medical Registrar, \\ Northern General Hospital, Sheffield
}

sequently showed evidence of disseminated lupus erythematosus. It is suggested that the aortic arch syndrome might have been due to involvement of the vasa vasorum of the arteries concerned in the course of disseminated lupus erythematosus, and that dissemination occurred after an interval, the initial symptoms and signs being also caused by this connective tissue disorder.

\section{Case report}

The patient is a housewife and accounting machine operator. She was first seen in the outpatient department in November 1956, when aged 25 years. She complained that for 6 weeks she had 